\title{
Evaluation of probiotic attributes of Lactobacillus sp. isolated from cow and buffalo curd samples collected from Kandy
}

\author{
M F F Shuhadha', G J Panagoda ${ }^{2}$, T Madhujith ${ }^{3}$, N W I A Jayawardana ${ }^{1}$
}

\begin{abstract}
Introduction Curd is a potential source of probiotic Lactobacillus species.

Methods This study was carried out to isolate and characterize Lactobacillus species available in curd samples sold in the market. Nine curd samples prepared using cow or buffalo milk were obtained from a local market in the Kandy district.
\end{abstract}

Results Seven isolates (LB 1-7) were identified based on their colony morphology and biochemical characteristics and evaluated for probiotic attributes such as low $\mathrm{pH}$ tolerance, resistance to bile salts, antimicrobial activity against Escherichia coli and Pseudomonas aeruginosa, antibiotic activity against erythromycin, chloramphenicol and norfloxacin, haemolytic activity and DNase activity. All isolates were able to grow at low $\mathrm{pH}(\mathrm{pH}=3.0)$ and were able to survive at $0.3 \%$ bile salt, however, the viability decreased with time. LB7 showed very low viability with bile salt compared to others. All isolates exhibited antimicrobial activity against the two pathogenic organisms tested. Two isolates (LB1 and LB2) showed maximum zone of inhibition $(18 \pm 1.13 \mathrm{~mm})$ against E.coli and four isolates (LB1, LB2, LB6 and LB7) against P.aeruginosa. Only LB6 and LB7 exhibited resistance to all three antibiotics tested while the other isolates were sensitive. In general, a higher sensitivity was shown against erythromycin and chloramphenicol compared to norfloxacin. All isolates exhibited $\delta$-haemolysis (non-haemolysis) while none of the isolates showed any DNase activity.

Conclusions Tested isolates showed probiotic attributes such as resistance to low $\mathrm{pH}$, tolerance to bile salt, antimicrobial resistance, antibiotic activity, non-haemolysis and no DNase activity.

Ceylon Medical Journal 2017; 62:159-166

DOI: http://doi.org/10.4038/cmj.v62i3.8519

\section{Introduction}

Probiotics are live microorganisms used as food supplements, which provide health benefits when consumed, by improving the intestinal microbial balance of the host [1]. Probiotics have been referred to as "live microorganisms which when administered in adequate amounts confer a health benefit on the host" [2]. Other physiological benefits of probiotics include removal of carcinogens, lowering of plasma cholesterol, immunostimulation and allergy lowering effect, synthesis and enhancing the bioavailability of nutrients and alleviation of lactose intolerance [3].

Most probiotic organisms are lactic acid bacteria (LAB) which comprise of a wide range of genera and include a considerable number of species especially Lactobacillus, Bifidobacterium and Enterococcus species [4]. These bacteria are the main component of the starters used in fermentation, especially for dairy products, and some of them are also present in the gastrointestinal microflora. In the food industry, LAB are widely used as starters to achieve favourable changes in texture, aroma, flavour and acidity [5]. Lactobacilli are one of the most important genera of LAB which are present in raw milk and dairy products such as cheeses, yoghurts and fermented milks [6]. In such products, lactobacilli are naturally present or added intentionally, for technological reasons or to generate a health benefit for the consumer. Curd is one product known to contain probiotics [6].

Lactobacilli comprise of a large and diverse group of gram positive, non spore forming, catalase negative rod bacteria, able to produce lactic acid as the main end product in the fermentation of carbohydrates [7]. They are generally recognized as safe (GRAS) organisms and can be safely used as probiotics for food, medical and veterinary applications [1].

\footnotetext{
${ }^{1}$ Department of Animal and Food Sciences, Faculty of Agriculture, Rajarata University of Sri Lanka.

${ }^{2}$ Department of Oral Medicine and Periodontology, Faculty of Dental Sciences, University of Peradeniya, ${ }^{3}$ Department of Food Science and Technology, Faculty of Agriculture, University of Peradeniya, Sri Lanka. Correspondence: MFFS, E-mail: <shuhadhaf@gmail.com>. Received 28 February 2017 and revised version accepted 24 July 2017.
} 
To be effective, probiotic bacteria must survive in the gastrointestinal tract, persist in the host, and prove safe for consumers [8]. Probiotics should be resistant to the environment of the gastrointestinal tract, thus should remain resistant for more than 4 hours to proteolytic enzymes, low $\mathrm{pH}$ values (1.8-3.2) prevailing in the stomach and to bile concentration, pancreatic juices and mucus which are part of the small intestine. Furthermore, bacterial strains used as probiotics are supposed to be resistant to antibiotics administered in animal diets and, should be producers of antimicrobial substances such as lactic acid, hydrogen peroxide and bacteriocins $[9,11]$.

\section{Methods}

Clay potted nine curd samples prepared from cow and buffalo milk were randomly collected from a local market in Kandy. Lactobacilli were isolated using quadrant streaking method under aseptic conditions. Streaked Petri plates were incubated at $37^{\circ} \mathrm{C}$ for 24 hours under anaerobic conditions. Subsequently purified cultures were obtained by sub culturing on Rogosa SL agar by incubating at $37^{\circ} \mathrm{C}$ for 24 to 48 hours.

\section{Identification and characterization of pure culture}

Morphological examination was carried out by using Gram's staining method [10]. Isolates were biochemically identified using endospore staining, motility test and catalase test.

\section{Endospore staining}

Endospores were stained by preparing a bacterial smear on microscopic slides which were heat fixed. Malachite green (primary stain) was applied and heat fixed. The slide was removed from the flame and rinsed with water until water ran clear. The slide was then flooded with the counter stain diluted carbol fuschsin for 30 seconds and rinsed with water. After that the slide was air dried and observed under the light microscope.

\section{Motility test}

Motility of strains was examined by "hanging drop method". A drop of bacterial culture was placed in the centre of a coverslip. A drop of paraffin was placed at each corner of the coverslip. A cavity slide was inverted over the coverslip so that it stuck to the slide and the drop of bacterial culture was suspended in the central depression of the cavity slide. Motile of the organisms were observed under microscope.

\section{Catalase test}

A drop of $3 \% \quad \mathrm{H}_{2} \mathrm{O}_{2}$ was put on a microscopic slide using an aseptic technique. A loopful of the bacterial culture was added on to the $3 \% \mathrm{H}_{2} \mathrm{O}_{2}$ solution on the slide and allowed to react Ceylon Medical Journal for 30 seconds. The presence of a bubble was recorded as catalase positive and absence as catalase negative. Non endospore forming, non motile, gram positive and catalase negative bacilli colonies were considered as Lactobacilli isolates.

\section{Probiotic characterization of pure culture}

Lactobacilli isolates were tested for resistance to low $\mathrm{pH}$, tolerance to bile salt, antimicrobial, antibiotic, haemolytic and DNase activity.

\section{Resistance to low $\mathrm{pH}$}

Resistance to low $\mathrm{pH}$ was examined by inoculating an overnight culture in MRS broth and incubating at $37^{\circ} \mathrm{C}$ for 24 hours. The culture broth was transferred into $10 \mathrm{ml}$ MRS broth adjusted to $\mathrm{pH}$ 3 with concentrated $\mathrm{HCl}$ and incubated at $37^{\circ} \mathrm{C}$ under anaerobic condition. Resistance was assessed in triplicates in terms of viable colony counts enumerated on Rogosa agar at $0,1,2,3$ and 4 hours. Petri plates were incubated at $37^{\circ} \mathrm{C}$ under anaerobic conditions for $48 \mathrm{hr}$. The survival rate of lactobacilli was observed for colonies grown on Rogosa agar compared to the initial bacterial concentration.

\section{Bile salt tolerance}

One $\mathrm{ml}$ of the culture incubated overnight was added to $10 \mathrm{ml}$ of $0.3 \%$ bile containing broth and incubated at $37^{\circ} \mathrm{C}$ under anaerobic condition. Viable colonies were counted hourly for 4 hours. Plates were incubated at $37^{\circ} \mathrm{C}$ under anaerobic condition for 48 hours.

\section{Antimicrobial activity}

Antimicrobial activity of the Lactobacillus sp. was determined using the disc diffusion method on nutrient agar against pathogenic strains Pseudomonas aeruginosa and Escherichia coli. The pathogenic strains were inoculated on nutrient agar plates using sterilized cotton swabs. Sterile paper blank discs of $9 \mathrm{~mm}$ diameter were dipped in fresh over night culture and placed on the surface of an agar plate. The petri plates were kept at $4{ }^{\circ} \mathrm{C}$ for 30 minutes to permit diffusion on the assay material, and incubated at $37^{\circ} \mathrm{C}$ for 24 hours. Zone of inhibition was measured in millimetres. The assay was repeated 30 times. Discs dipped in sterile water served as a control.

\section{Antibiotic activity}

Antibiotic activity of isolates was tested by spreading the fresh overnight cultures evenly on the surface of Rogosa agar plates using sterile cotton swabs. Antibiotic paper discs were placed on the agar plates at $4^{\circ} \mathrm{C}$ for 30 minutes for diffusion of antibiotics. The antibiotic discs used were streptomycin and gentamycin. Discs dipped in sterile water served as controls. The plates were then 
anaerobically incubated at $37^{\circ} \mathrm{C}$ for 24 hours. The measurement of the diameter of the zone of inhibition included the diameter of the discs.

\section{Haemolytic activity}

Haemolytic activity of isolates was tested using blood agar base with 10\% human blood. Fresh overnight cultures were streaked on blood agar plates and incubated at $37^{\circ} \mathrm{C}$ for 24 hours in anaerobic jars. After incubation, agar plates was observed for zones around the colonies. The assay was repeated 30 times.

\section{DNase test}

DNase test was done by inoculating fresh overnight broth culture on DNase agar and incubated at $37{ }^{\circ} \mathrm{C}$ for $24 \mathrm{hr}$. After incubation, DNase agar plate was flooded with $\mathrm{HCl}$ and excess was removed. After $5 \mathrm{~min}$, agar plate was observed for "halo" appearance surrounding the strains. The assay was repeated for 30 times.

\section{Data analysis}

Data was analysed using analysis of variance (ANOVA) to see the differences between means using Minitab software.

\section{Results}

Seven isolates were obtained from curd samples using the streak plate method. LB1, LB2 and LB3 were obtained from refrigerated buffalo curd samples. LB4, LB5 and LB6 were obtained from non-refrigerated buffalo curd samples. LB 7 was obtained from non-refrigerated cow curd samples and no isolates were found in the nonrefrigerated cow curd samples.

\section{Identification of pure culture}

Isolated colonies were characterized and identified based on their colony morphology and biochemical characteristics (Table 1). Most of the colonies were small, smooth and white-cream in colour while colony LB6 had a rough texture. Microscopy showed that they were Gram-positive, rod shaped, non-motile, catalase negative and did not have endospores.

\section{Resistance to low $\mathrm{pH}$}

Resistance to low $\mathrm{pH}$ was measured by the number of colonies which were resistant to $\mathrm{pH}=3$, for 4 hours of incubation. According to the results, all isolates showed the ability to grow at low $\mathrm{pH}$ $(\mathrm{pH}=3)$. The viability of isolates decreased with time. Most of the isolates showed significant growth at $\mathrm{pH}$ 3.0 even after 5 hours of incubation. However, the number of viable colonies decreased. All isolates were viable at the end of 5 hours (figure 1).

\section{Resistance to bile salt}

All isolates were able survive $0.3 \%$ bile salt concentration, however the viability decreased with time. After 2 hours of incubation, a drastic reduction in viability was observed in all isolates. Figure 2 illustrates the variation in the resistance to bile salt of the seven isolates after 2 hours of incubation. LB6 showed the most growth compared to other isolates whereas, LB7 showed no growth at 2 hours of incubation.

\section{Antimicrobial activity}

Antimicrobial activity of the isolates against pathogenic organisms Escherichia coli and Pseudomonas aeruginosa was assessed by measuring the diameters of the zone of inhibition. Two isolates (LB1 and LB2) exhibited maximum zone of inhibition against E.coli $(17.89 \pm 0.80$ and $17.78 \pm 0.25$ ) while four isolates (LB1, LB2, LB6 and LB7) exhibited maximum zone of inhibition against P. aeruginosa (Table 2).

Antibiotic activity
Antibiotic
resistance was tested using
antibiotic discs containing erythromycin, chloramphenicol and norfloxacin using the disc diffusion method. LB6 and LB7 isolates exhibited resistance to all three antibiotics while the other isolates were sensitive. In general, a higher sensitivity was shown against erythromycin and ciprofloxacin compared to norfloxacin. LB4 showed significant differences against both erythromycin and chloramphenicol compared to other isolates $(p<0.05)$. LB2 showed significant difference against norfloxacin (Table 3) $(p=0.05)$.

\section{Haemolytic activity}

This study showed that all the tested isolates exhibited $\delta$-haemolysis (non-haemolysis) which is considered a safety characteristic of probiotic bacteria.

\section{DNase activity}

None of the isolates showed any DNase activity. Staphylococcus aureus was used as control strain.

\section{Discussion}

Based on the morphological and biochemical characteristics, the isolates were identified as Lactobacillus sp. All isolates were gram positive, rod shaped, non-spore forming, non-motile and catalase negative while LB6 had long rods compared to other isolates. These results are comparable with the research reported by Patil et al. [12].

The probiotic isolate must travel through the human stomach and survive at $\mathrm{pH} 1.5-2.0$, before 
reaching the intestine to colonise it [13]. Survivability of the isolates at low $\mathrm{pH}$ and high levels of bile allows probiotics to survive transit through the stomach and reach the intestine thus maintaining gut flora. As they establish in the gastrointestinal tract, the microorganisms activate their metabolic pathways resulting in the release of some organic molecules which are beneficial to the host. There is a significant decrease in the viability of the strains is at $\mathrm{pH} 2.0$ and below [16]. Therefore, $\mathrm{pH} 3.0$ is set as the standard for screening for acid tolerance $[14,15]$.

One study reported acid tolerance of L.acidophilus and Bifidobacterium strains at pH 2. However, another study reported that there were no viable cells at $\mathrm{pH} 2$ after 30 minutes, but, at $\mathrm{pH} 3$, the number of viable Lactobacillus acidophilus cells decreased with time, while in Lactobacillus casei, the number of viable cells were constant at $\mathrm{pH} 3$ [17].

Abriouel et al. showed all lactic acid bacteria isolated from fermented olive were able to grow and survive at $0.3 \%$ bile salt [18]. The tolerance level of bile salt was based on the intestinal bile concentration of $0.3 \%$ and the duration of passage of food through the small intestine of 4 hours [19]. High levels of bile salt in the body aids in lipid metabolism, at the same time it denatures the membranes of probiotics and thereby reduces its benefits to host. However, survivability at high bile concentrations is necessary for lactic acid bacteria to survive in the small intestine. During the first hour of digestion the bile level is nearly $2.0 \%$. The average concentration of bile is $0.3 \%$. Hence, $0.3 \%$ was considered as the critical concentration for screening for resistance in isolates which can be used as probiotics [20].

Lactic acid bacteria can produce antimicrobial substances such as organic acids, hydrogen peroxide and diacetyl which are capable of inhibiting the growth of pathogenic and spoilage microorganisms [21]. Bassyouni et al. showed that Lactobacillus species tested against E.coli, Salmonella sp. and Staphylococcus sp. showed antibacterial effect [22]. Salminen et al. also reported that the capacity to produce different antimicrobial compounds may be one of the critical characteristics for effective competitive exclusion of pathogen survival in the intestine and expression of a probiotic effect of a host [23].

The resistance of probiotics to antibiotics helps in replenishing normal microflora in an individual after treatment with antibiotics. Probiotics have been used to prevent antibiotic associated diarrhoea, which is due to imbalance in the gut microflora caused by antibiotics [24]. Many strains of lactobacilli are naturally resistant to vancomycin. It is accepted that antibiotic nonsusceptibility/resistance is not, in itself, a hazard unless it renders the probiotic untreatable in rare cases of infection or unless it can be transferred to potential pathogens, in which case resistance could have therapeutic consequences. The vancomycin resistant genes of Lactobacillus species are not easily transferable to other genera [25]. Vancomycin cannot be used for the treatment of lactobacillemia. When used as probiotics, the selected strains should be susceptible to a minimum of two antibiotics. It is difficult to interpret studies of gene transfer in vivo, and the methods involved need to be further developed.

D'Aimmo et al. reported that, lactobacilli are resistant to nalidixic acid, aztreonam, cycloserin, kanamycin, metronidazole, polymyxin B, spectinomycin and susceptible to rifampicin, bacitracin, clindamycin, erythromycin, novobiocin and penicillin [26]. Danielsen and Wind showed that lactobacilli have high natural resistance to bacitracin, cefoxitin, ciprofloxacin, fusidic acid, kanamycin, gentamicin, metronidazole, nitrofurantoin, norfloxacin, streptomycin, sulphadiazine and teicoplanin [27].

Non-haemolytic activity (clear zones around colonies) of probiotic isolates are considered as a safety prerequisite for selection as a probiotic organism. Maragkoudakisa showed that L.casei, L.delbruekii and L.lactis show $\delta$-haemolysis [28]. Another study showed that L.casei, L.delbruekii and L.lactis were $\delta$-haemolytic while L.coagulans and L.rhamnosus exhibited $\alpha$ - haemolysis (green zones around colonies) [29].

DNase activity of Lactobacilli isolates grown on DNase agar was examined for the hydrolysis of DNA molecules. It was determined by observing "halo" appearance surrounding the isolates after applying $\mathrm{HCl}$ solution. In 1956, Weckman and Catlin [30] suggested that DNase activity could be used to identify potentially pathogenic staphylococci.

\section{Conclusion}

The isolated bacteria were rod shaped, gram positive, non-spore forming and non-motile and were therefore confirmed as Lactobacillus species. None of the isolates produced catalase enzyme. The isolates showed probiotic attributes such as resistance to low $\mathrm{pH}$, tolerance to bile salts, antimicrobial resistance, antibiotic activity, nonhaemolysis and no DNase activity. No significant difference of probiotic attributes was observed between refrigerated and non-refrigerated curd. Further investigations are recommended to identify the Lactobacilli strains available in these isolates. 


\section{Acknowledgements}

We are grateful to the staff of the Division of Microbiology, Faculty of Dental Sciences, University of Peradeniya for their support and valuable technical assistance.

\section{Conflicts of interest}

There are no conflicts of interest.

\section{References}

1. Fuller R. Probiotic in man and animals. A Review J Appl Bacteriol 1989; 90: 3452-3.

2. FAO/WHO Working Group Report. (2002). Guidelines for the evaluation of probiotics in food. London, Ontario, Canada.

3. Parvez S, Malik KA, Ah Kang S, Kim HY. Probiotics and their fermented food products are beneficial for health. $J$ Appl Microbiol 2006; 100: 1171-85.

4. Klein G, Pack A, Bonaparte C, Reuter G. Taxonomy and physiology of probiotic lactic acid bacteria. Int $J$ Food Microbiol 1998; 41: 103-25.

5. Leroy F, De Vuyst L. Functional lactic acid bacteria starter cultures for the food fermentation industry. Trends in Food Science and Technology 2004; 15: 6778.

6. Coeuret V, Dubernet S, Bernardeau M, Gueguen M, Vernoux JP. Isolation, characterisation and identification of lactobacilli focusing mainly on cheeses and other dairy products. Le Lait, INRA Editions 2003; 83: 269- 306.

7. Pelinescu DR, Sasarman E, Chifiriuc MC, et al. Isolation and identification of some Lactobacillus and Enterococcus strains by a polyphasic taxonomical approach. Romanian Biotechnological Letters 2009; 14: 4225-33.

8. De Vries MC, Vaughan EE, Kleerebezem M, de Vos WM. Lactobacillus plantarum survival, functional and potential probiotic properties in the human intestinal tract. Int. Dairy J. 2006; 16: 1018-28.

9. Gorbach SL, Goldin BR. Lactobacillus acidophilus United States Patent, (5). 1991; 32: 399.

10. Gram HC, (1884). "Über die isolierte Färbung der Schizomyceten in Schnitt- und Trockenpräparaten". Fortschritte der Medizin (in German). 1884; 2: 185-9.

11. Hoyos G. Aplicación de la biotecnología en la producción animal: La experiencia mexicana de una década. Memorias del 1er Simposio Mexicano sobre Probióticos 1997; 131-48.
12. Patil MM, Pal A, Anand A, Ramana VK. "Iso- lation and Characterization of Lactic Acid Bacteria from Curd and Cucumber," Indian J Biotech 2010; 9: 166-72.

13. Dunne $\mathrm{C}, \mathrm{O}^{e e}$ Mahony L, Murphy L, et al. In vitro selection criteria of probiotic bacteria of human origin: correlation with in vivo findings 2001.

14. Dave RI, and Shah NP. Ingredient supplementation effects on viability of probiotic bacteria in yogurt $J$ Dairy $\mathrm{Sci}$ 1998; 81: 2804-16.

15. Sahadeva RPK, Leong SF, Chua KH. Survival of commercial probiotic strains to pH and bile. Int Food Res J 2011; 18: 151522.

16. Prasad J, Gill H, Smart J, Gopal PK. Selection and characterisation of Lactobacillus and Bifidobacterium strains for use as probiotics. Int Dairy J 1998; 8: 993-1002.

17. Both E, Gyorgy E, Kibedi-Szabo CZ, Tamas E. Acid and bile tolerance, adhesion to epithelial cells of probiotic microorganisms. UPB Scientific Bulletin 72, 2010.

18. Abriouel H, Benomar N, Cobo A, Caballero N, Fernandez Fuentes MA, Perez-Pulido R, Galvez A. Characterization of lactic acid bacteria from naturally-fermented Manzanilla Alorena green table olives. Food Microbiol 2012; 32: 308-16.

19. Kumar AM, Murugalatha N. Isolation of Lactobacillus planatarum from cow milk and screening for the presence of sugar alcohol producing gene. J Food Microbiol and Antimicrobiol 2012; 4: 16-22.

20. Gilliland SE, Staley TE, Bush LJ. Importance of bile tolerance of Lactobacillus acidophilus used as a dietary adjunct. J Dairy Sci 1984; 67: 3045-6051.

21. Yuksekdag ZN, Aslim B. Assessment of potential probiotic and starter properties of Pediococcus spp. isolated from TurkishType fermented sausages (Sucuk). $J$ Microbiol and Biotechnol 2010; 20:161-8.

22. Bassyouni RH, Abdel-all WS, Fadl MG, Abdel-all S, Kamel Z. Charaterization of Lactic Acid Bacteria Isolated from Dairy Products in Egypt as a Probiotic. Life Sci 2012; 9: 2924-30.

23. Salminen S, von Wright A, Morelli L, Marteau P, Brassart D, de Vos WM, Fonden R, Saxalin M, Collins K, Mogensen G, Birkeland SE, Mattila-Sandholm T. Demonstration of Safety of Probiotics. Int $J$ Food Microbiol 1998; 44: 93-106.

24. Adagbada AO, Adesida SA, Akitoye CO. Antibacterial potentials of probiotics, Asian 
J. Pharmaceuticals and Health Sci 2012; 2: 346-51.

25. Tynkkynen S, Singh KV, Varmanen $\mathrm{P}$. Vancomycin resistance factor of Lactobacillus rhamnosus GG in relation to enterococcal vancomycin resistance (van) genes. Int J Food Microbiol 1998; 41: 195204.

26. D’Aimmo MR, Modesto M, Biavati B. Antibiotic resistance of lactic acid bacteria and Bifidobacterium spp. isolated from dairy and pharmaceutical products. Int $J$ Food Microbiol 2007; 115: 35-42.

27. Danielsen M, Wind A. Susceptability of Lactobacillus spp. to antimicrobial agents. Int Food Microbiol 2003; 82: 1-11.
28. Maragkoudakis PA, Zoumpopoulou G, Miaris C, Kalantzopoulos G, Pot B, Tsakalidou E. Probiotic potential of Lactobacillus strains isolated from dairy products. Int Dairy J 2006; 16: 189-99.

29. Hawaz E. Isolation and Identification of Probiotic Lactic Aid Bacteria from Curd and in vitro Evaluation of its Growth Inhibition Activities against Pathogenic Bacteria. African J Microbiol Res 2014; 8: 1419-25.

30. Weckman BG, Catlin BW. Deoxyribonuclease activity of micrococci from clinical sources. $J$ Bacteriol 1957; 73: 747-53. 
Table 1. Morphological and biochemical characteristics of seven isolates

\begin{tabular}{cccccc}
\hline Isolate & Colony morphology & $\begin{array}{c}\text { Gram } \\
\text { staining }\end{array}$ & $\begin{array}{c}\text { Endospore } \\
\text { staining }\end{array}$ & $\begin{array}{c}\text { Motility } \\
\text { test }\end{array}$ & Catalase test \\
\hline LB1 & White-creamy, smooth & + rods & - & - & - \\
LB2 & White-creamy, smooth & + rods & - & - & - \\
LB3 & White-creamy, smooth & + rods & - & - & - \\
LB4 & Creamy, smooth & + rods & - & - & - \\
LB5 & White-creamy, smooth & + rods & - & - & - \\
LB6 & White-creamy, rough & Long rods & - & - & - \\
LB7 & White-creamy, smooth & +rods & - & - & - \\
\hline
\end{tabular}

Table 2. Antimicrobial activity of seven isolates obtained from curd samples

\begin{tabular}{|c|c|c|}
\hline \multirow[t]{2}{*}{ Isolate } & \multicolumn{2}{|c|}{$\begin{array}{c}\text { Diameter of zone of inhibition (mm) } \\
\text { Mean (SD) }\end{array}$} \\
\hline & P.aeruginosa & E.coli \\
\hline LB1 & $17.89 \pm 0.80$ & $18.29 \pm 0.51$ \\
\hline LB2 & $17.78 \pm 0.25$ & $17.58 \pm 0.11$ \\
\hline LB3 & $16.11 \pm 0.36$ & $16.88 \pm 0.22$ \\
\hline LB4 & $14.78 \pm 0.53$ & $13.64 \pm 0.1$ \\
\hline LB5 & $16.78 \pm 0.26$ & $15.05 \pm 0.15$ \\
\hline LB6 & $17.62 \pm 0.40$ & $15.23 \pm 0.45$ \\
\hline LB7 & $18.89 \pm 0.16$ & $16.05 \pm 0.26$ \\
\hline
\end{tabular}

Table 3. Antibiotic resistance of Lactobacilli isolates obtained from curd samples against three isolates

\begin{tabular}{cccc}
\hline Isolate & \multicolumn{3}{c}{$\begin{array}{c}\text { Diameter of zone of inhibition (mm) } \\
\text { Mean (SD) }\end{array}$} \\
\cline { 2 - 4 } LB1 & Erythromycin & Chloramphenicol & Norfloxacin \\
LB2 & $19 \pm 0.57$ & $21 \pm 0.57$ & $23 \pm 0.57$ \\
LB3 & $29 \pm 0.57$ & $27 \pm 0.57$ & $7 \pm 1.15$ \\
LB4 & $21 \pm 0.57$ & $20 \pm 0.57$ & $17 \pm 0.57$ \\
LB5 & $31 \pm 1.73$ & $30 \pm 1.15$ & $24 \pm 0.57$ \\
LB6 & $14 \pm 0.57$ & $17 \pm 1.00$ & 0 \\
LB7 & 0 & 0 & 0 \\
\hline
\end{tabular}




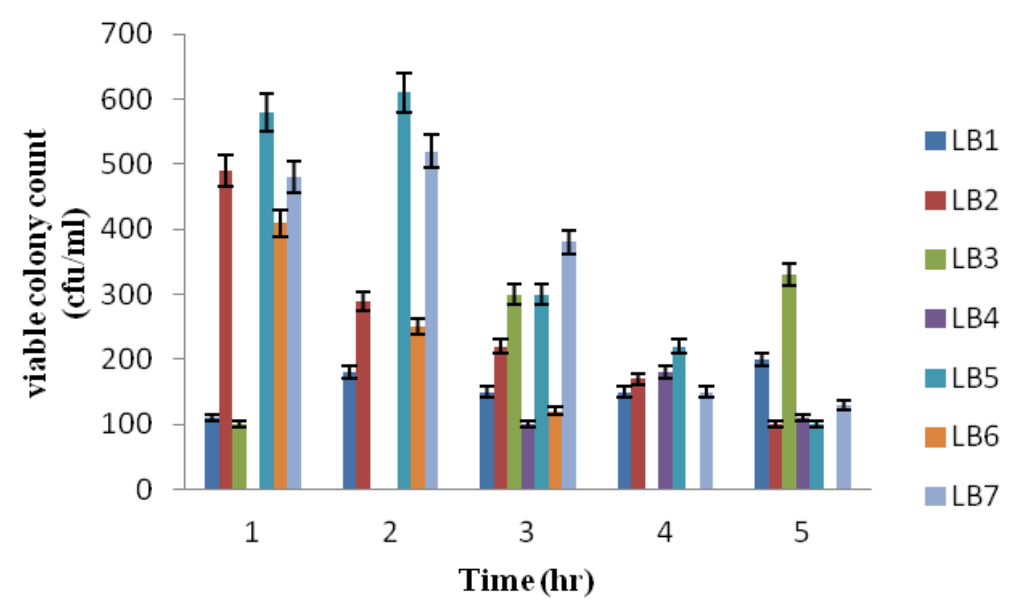

Figure 1. Survival rate of Lactobacilli isolates at pH 3.0

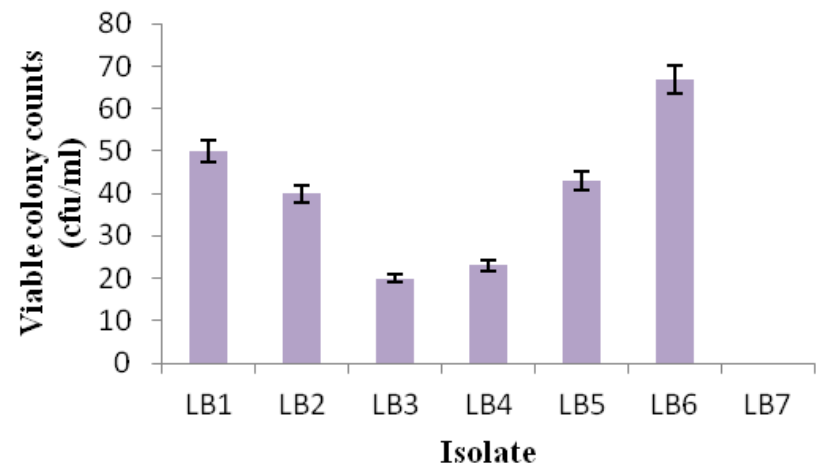

Figure 2. Bile salt tolerance of Lactobacilli isolates at $\mathbf{2}$ hours of incubation

c) (7) This is an open-access article distributed under the terms of the Creative Commons Attribution License, which permits unrestricted use, distribution, and reproduction in any medium, provided the original author and source are credited. 